\title{
The effects of substrate dilution on the microstructure and wear resistance of PTA Cu- Al-Fe aluminium bronze coatings
}

\author{
P. Kucita ${ }^{1}$, S.C. Wang ${ }^{1 *}$, W.S. Li ${ }^{2}$, R.B. Cook ${ }^{1}$ and M.J. Starink ${ }^{3}$
}

${ }^{1}$ National Centre for Advanced Tribology at Southampton, School of Engineering, University of Southampton, University Road, Southampton, SO17 1BJ, United Kingdom

${ }^{2}$ State Key Laboratory of Advanced Non-ferrous Materials, Lanzhou University of Technology, China

${ }^{3}$ Engineering Materials, School of Engineering, University of Southampton, University Road, Southampton, SO17 1BJ, United Kingdom

*corresponding author, wangs@soton.ac.uk

\begin{abstract}
$\mathrm{Cu}-\mathrm{Al}-\mathrm{Fe}$ aluminium bronze alloys are good candidates for precious tools and forming dies due to their high wear resistance, good sliding properties and low tendency for adhesion to ferrous metals. Plasma transferred arc (PTA) is an effective process for deposition of such robust coatings by enhancing the bond between the bronze coating and steel substrate. However, the microstructure and wear characteristics of these coatings are strongly influenced by the diffusion of substrate elements (mostly iron) to the interface. In the present study, the effects of substrate dilution on the microstructure and wear behaviour of $\mathrm{Cu}-\mathrm{Al}-\mathrm{Fe}$ alloy deposited by PTA on medium carbon steel substrate were investigated. The results show that the deposition current controls the melting temperature and iron dilution which result in the formation of $\mathrm{Cu}_{3} \mathrm{Al}$ martensitic $\beta_{1}$ phase in a low dilution and the ordered $\beta_{1}$ phase in high dilution. The wear behaviour of the coating is dominated by failure of the matrix phase. Low dilution coating with martensitic phase exhibits the highest wear resistance. On high diluted Fe rich coating, pile up of dislocation on the intermetallic $\mathrm{K}$ phase leads to surface cracks and delamination of the coating resulting in a high wear rate.
\end{abstract}

Keywords: Cu-Al-Fe; Bronze coatings; Plasma transferred arc; Dilution; Sliding wear. 


\section{Introduction}

Sheet metal forming is an important manufacturing process used in many industries to produce parts by plastic deformation of sheet metals using tools and dies. During forming, high contact pressure and insufficient lubrication often lead to material transfer from the sheet metal to the dies resulting in severe scratching of the sheet metal and wear of the dies. This problem is commonly referred to as galling [1] and is particularly severe during the forming of high strength stainless steel, titanium alloy as well as in the hygienic industries such as food processing where limited lubricant can be used $[2,3]$.

To protect the forming dies, surface coatings are frequently employed. Amongst the different coating materials, the $\mathrm{Cu}-\mathrm{Al}-\mathrm{Fe}$ aluminium bronze alloy exhibits high wear resistance, good sliding properties and low tendency for adhesion to ferrous metals [4]. This makes it an ideal coating material for precision forming of stainless steel. Several coating deposition techniques have been used to coat the surface of the forming dies. The plasma transferred arc (PTA) technique is one of the most widely used as it allows for controlled deposition of high quality and thick coating with strong metallurgical bonding between the coating and substrate. However, the coating and substrate material are mixed in the weld pool leading to a change in chemical composition of the coating. This is often referred to as dilution [5]. Low dilution results in a coating with composition close to that of the precursor material, however, high dilution is often preferred as this increases the adhesion between the coating and the substrate at the expense of reduced wear resistance and mechanical properties. Fernandes et al. [6] investigated the effects of dilution on the microstructure and high temperature wear characteristic of a Ni-based coating. Their results show that at room temperature, the wear loss is independent of dilution. However, at high temperature, high dilution coating displayed maximum wear resistance due to formation of protective tribo-layer. Leandro et al. [7] studied the effects of dilution on the microstructure and high temperature wear of $\mathrm{NiCrSiBC}$ coating. Their results show that the increase of dilution prevents formation of $\mathrm{Cr}_{5} \mathrm{~B}_{3}$ borides, which results in the decrease of hardness and accordingly less wear resistance. Sawant and Jain [8] concluded that low dilution leads to higher micro hardness and low friction coefficient of $\mathrm{CoCr}$ based Stellite coating.

Aluminium bronze alloys form an important category of bronze used in many tribological applications. The microstructure and wear resistance of aluminium bronze alloys are complex and strongly dependent on the composition and cooling rate during production. In this alloy system, an ordering reaction [9], martensitic transformation [10] and formation of intermetallic compounds have been reported. This makes the microstructure and tribological characteristics of the alloy highly complex due to the presence of multiple phases in the alloy. The majority of the investigations by far mainly focused on aluminium bronze alloys. There are few research on the matrix Fe diffusion into aluminium bronze coatings, in 
particular for those with $\mathrm{Fe}>5 \mathrm{wt} . \%$ little detailed work has been published. This study aims to investigate the effects of increasing dilution on the microstructure and wear characteristic of PTA Cu$14.5 \mathrm{Al}-4.5 \mathrm{Fe}$ (wt.\%) coatings on medium carbon steel substrate, and to optimize the effects of dilution on the microstructure and wear resistance.

\section{Materials and Methodology}

\subsection{Coating deposition}

The $\mathrm{Cu}-14 \mathrm{Al}-4.5 \mathrm{Fe}$ aluminium bronze powders $50-150 \mu \mathrm{m}$ in diameter were produced by gas atomisation in nitrogen atmosphere and cooling water as detailed in [11]. The powders were subsequently deposited on to an E.N. 10503 medium carbon steel (hardness of $195 \mathrm{HV}$ ) substrate ( $108 \mathrm{~mm}$ x $20 \mathrm{~mm}$ ) by PTA technique. The chemical compositions of the aluminium bronze powder and the substrate are presented in Table 1.

Table 1: Nominal composition of $\mathrm{Cu}-14 \mathrm{Al}-4.5 \mathrm{Fe}$ aluminium bronze powder and E.N. 10503 steel substrate (all in wt.\%)

\begin{tabular}{l|llllllll}
\hline & $\mathrm{Cu}$ & $\mathrm{Al}$ & $\mathrm{Fe}$ & $\mathrm{Mn}$ & $\mathrm{Ni}$ & $\mathrm{Si}$ & $\mathrm{Cr}$ & $\mathrm{C}$ \\
\hline $\mathrm{Cu}-14 \mathrm{Al}-4.5 \mathrm{Fe}$ & 76.9 & 15.5 & 4.6 & 1.2 & 0.6 & 0.2 & 0.2 & - \\
\hline E.N. 10503 & - & - & $\mathrm{Bal}$ & $0.5-0.8$ & - & $0.2-0.4$ & - & $0.4-0.5$ \\
\hline
\end{tabular}

Four different deposition currents ranging from 165 A to 220 A were used to produced coatings with increasing levels of dilution. The other process parameters were fixed as detailed in Table 2. For all coatings, the final thickness is approximately $5 \mathrm{~mm}$. Following the deposition the samples were left cool down in still air at room temperature.

Table 2: PTA deposition parameters

\begin{tabular}{l|l}
\hline Deposition current & $165-220 \mathrm{~A}$ \\
\hline Nitrogen flow rate & $3-6 \mathrm{~L} \mathrm{~min}^{-1}$ \\
\hline Powder feed rate & $1-3 \mathrm{~g} \mathrm{~s}^{-1}$ \\
\hline Torch working distance & $10 \mathrm{~mm}$ \\
\hline Stage rotation speed & $0.05 \mathrm{rpm}^{-1}$ \\
\hline Nozzle speed (x-direction) & $15 \mathrm{~mm} \mathrm{~s}^{-1}$ \\
\hline
\end{tabular}

\subsection{Microstructure characterisation approach}

Specimens for microstructure characterisation were grounded up to 4000 grit $\mathrm{SiC}$ and polished with 6 $\mu \mathrm{m}$ and $1 \mu \mathrm{m}$ diamond pastes. To reveal the different microstructures, electro-polishing was performed using $20 \% \mathrm{HNO}_{3}+15 \%$ 2-butoxyethanol $+65 \%$ methanol solution at $-30^{\circ} \mathrm{C}$. Polishing time was $30 \mathrm{~s}$ at $20 \mathrm{~V}$. The microstructures were examined using a JEOL-JSM6500F scanning electron microscope 
(SEM) operating at $15 \mathrm{kV}$ and a working distance of $10-11 \mathrm{~mm}$. The SEM is equipped with a HKL Channel 5 Electron Backscatter Diffraction (EBSD) system and an Oxford Inca Energy dispersive Xray Spectroscopy (EDS) system. EBSD mapping was carried out with an accelerating voltage of $15 \mathrm{kV}$ and a working distance of $18 \mathrm{~mm}$. Step sizes of $500 \mathrm{~nm}$ was employed. All samples for EBSD analysis were prepared by electro-polishing. X ray diffraction was carried out using a PXD Benchtop D2 Phaser with $\mathrm{Cu} K_{\alpha}(\lambda=0.154056 \mathrm{~nm})$ radiation. The scanning rate used was $0.02 \% \mathrm{~s}$ and step of $5 \mathrm{~s}$. Depthsensing nano indentation was employed to produce a hardness map of the coating surface. The nano indenter was operated in depth control mode using a Berkovich indenter tip. The initial load of 0.02 $\mathrm{mN}$, cut off load of $0.1 \mathrm{mN}$, the dwell time at maximum depth of $40 \mathrm{~s}$, loading/unloading rate of $1 \mathrm{mN}$ $\mathrm{s}^{-1}$ and maximum depth of $500 \mathrm{~nm}$ was used. Each map consists of 196 indents. The spacing between each indent is $\sim 15 \mu \mathrm{m}$. Melting of the steel substrate promoted during PTA deposition leads to an increase in Fe content in the coating. The amount of substrate dilution was calculated using (1 [7].

$$
\text { Dilution }(\%)=\frac{\mathrm{Fe}_{\text {coating }}-\mathrm{Fe}_{\text {powder }}}{\mathrm{Fe}_{\text {substrate }}-\mathrm{Fe}_{\text {powder }}}
$$

\subsection{Dry sliding wear tests}

Specimens for tribological tests were also grounded up to 4000 grit $\mathrm{SiC}$ and polished with $6 \mu \mathrm{m}$ and 1 $\mu \mathrm{m}$ diamond pastes to achieved a uniform roughness with $\mathrm{Ra} \sim 0.1 \mu \mathrm{m}$. The dry sliding friction and wear characteristics of the coatings were evaluated at room temperature and relative humidity of $40 \pm$ 5\% using a reciprocating tribometer (Phoenix Tribology TE-77 High Frequency Reciprocating tribometer). Sliding speed of $0.1 \mathrm{~mm} \mathrm{~s}^{-1}$, stroke length of $5 \mathrm{~mm}$, test duration of 30 minutes and a load range from $5 \mathrm{~N}$ to $20 \mathrm{~N}$ were employed. AISI 52100 bearing steel balls with a diameter of $6 \mathrm{~mm}$ and $\mathrm{Ra} 0.13 \mu \mathrm{m}$ were used as counter material. The test parameters were selected to produce measureable wear on the samples. The mass loss of the coating was measured by a Sartorius ME-2355 high precision scale with sensitivity $\pm 0.01 \mathrm{mg}$ and is then converted into volume by using the density of the material. The density of the coating was taken as $8.70 \mathrm{~g} \mathrm{~cm}^{-3}$ [12]. The morphology and chemical composition of the worn surfaces were also observed using SEM and EDS analyses. Selected surfaces were also sectioned using Zeiss NV40 SEM equipped with Focused Ion Beam (FIB) operating at a working distance of $5.1 \mathrm{~mm}, 54^{\circ}$ tilt. The samples were milled using probe current of $700 \mathrm{pA}$ and subsequently polished using a probe current of $80 \mathrm{pA}$.

\section{Results}

\subsection{The effects of dilution on the microstructure of PTA aluminium bronze coatings}

During PTA deposition, the aluminium bronze powder and the medium carbon steel substrate were melted and mixed together in the weld pool leading to a significant increase of Fe content as shown in Table 3, with the corresponding dilution calculated from (1. The amount of dilution increased with the deposition current as expected. At higher current, more heat would be generated to melt the substrate 
which resulted in higher dilution $[13,14]$. From here onwards, the coatings $(1-4)$ are referred to the dilution percentages shown in Table 3.

Table 3: Nominal composition of the as-deposited PTA aluminium bronze coating evaluated by SEMEDS (all in wt.\%)

\begin{tabular}{c|l|cccc}
\hline & & $\mathrm{Cu}$ & $\mathrm{Al}$ & $\mathrm{Fe}$ & Dilution (\%) \\
\hline Increasing & Coating 1 & 75.7 & 12.2 & 9.2 & 5 \\
deposition current & Coating 2 & 67.3 & 8.4 & 21.5 & 18 \\
& Coating 3 & 62.7 & 8.7 & 27.4 & 24 \\
& Coating 4 & 54.8 & 6.8 & 35.3 & 34 \\
\hline
\end{tabular}

The backscattered electron (BSE) images of the cross section through the coating and steel substrate and the corresponding EDS elemental mapping are shown in Figure 1. Under backscattered electron imaging, the Cu-rich coating appears brighter than the Fe-rich steel substrate. This leads to a clearly defined $\mathrm{Fe}-\mathrm{Cu}$ boundary (shown by the yellow lines in Figure 1). As the Fe content in the coating increases, Fe-rich dendrites were observed to protrude from the Fe-Cu boundary as shown by the BSE image and EDS mapping in Figure 1c, d. Besides the cooper rich matrix, iron rich intermetallic compound are clearly in dark contrast. Their contents and sizes enhanced with the increase of dilutions. In the low dilution (5\% in Figure 1a), most of Fe rich intermetallic compounds were submicron size throughout the matrix. These fine intermetallic compounds became micron and/or tens micron in size at high dilutions (Figure 1b-d). The intermetallics are rich in $\mathrm{Fe}$ and $\mathrm{Al}$ with stoichiometric ratio close to 3:1. In combination with XRD (Figure 3), the intermetallic compounds were identified as the $\mathrm{Fe}_{3} \mathrm{Al}$ intermetallic $\mathrm{K}$ phase of $\mathrm{D}_{3}(\mathrm{Fm} \overline{3} \mathrm{~m})$ structure and lattice parameter $a=0.578 \mathrm{~nm}$. With increasing dilution, the size of the intermetallic $\mathrm{Fe}_{3} \mathrm{Al} \mathrm{K}$ increased from sub-microns (Figure 2a) to tens of microns (Figure 2d). In the coating with the highest dilution in Figure 2d, an additional phase was observed in light grey as $\mathrm{Fe}(\mathrm{Al})$ solid solution phase with the bcc structure and $a=0.290 \mathrm{~nm}$, confirmed by the XRD in Figure 3d. Within these Fe-rich intermetallic compounds, fine precipitates appearing bright were clearly resolved in Figure 2b-d and confirmed as $\alpha-\mathrm{Cu}$ by EDS. 


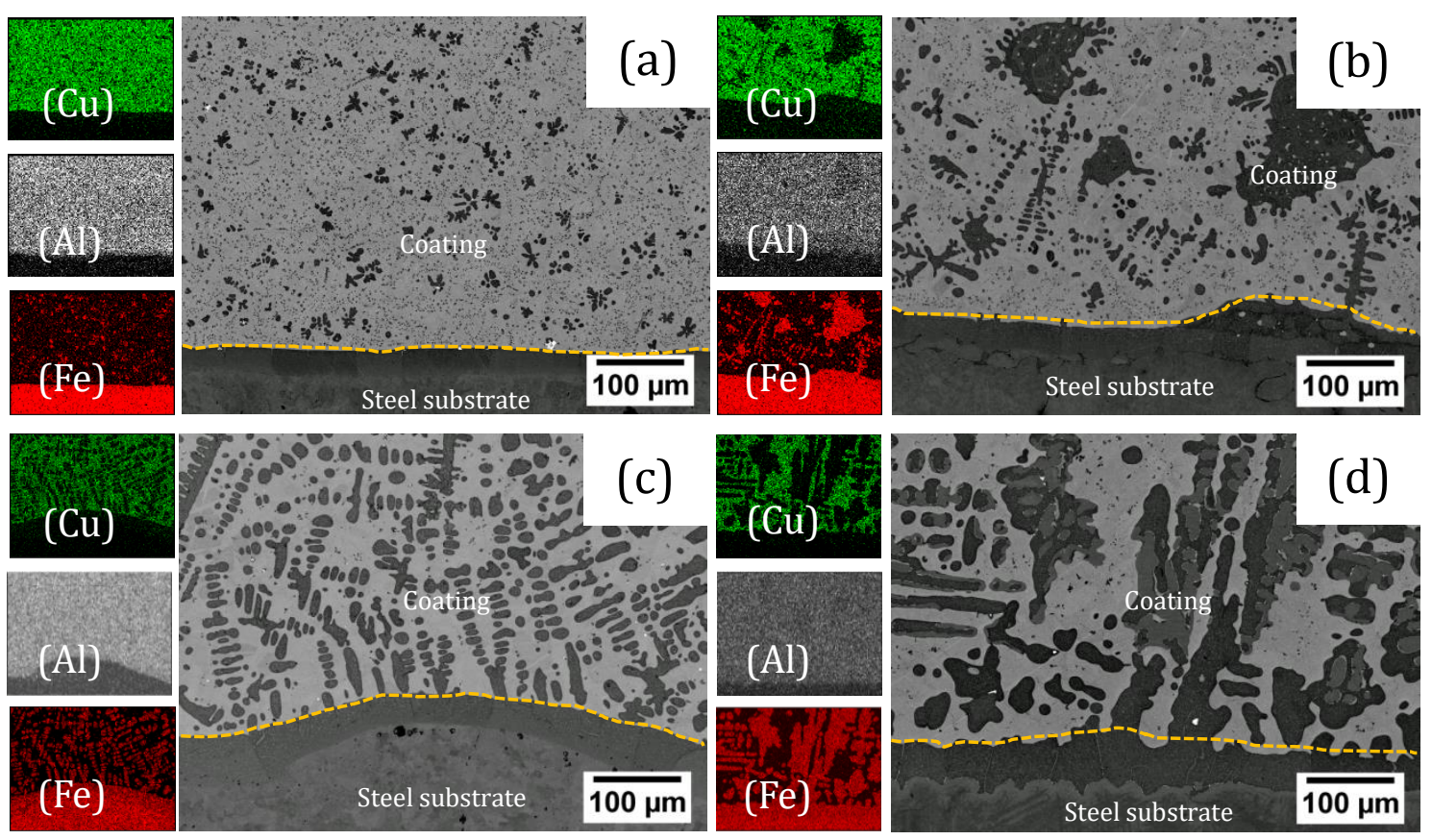

Figure 1: BSE image and EDS element analysis of the section through the coating-steel substrate interface for coatings of increasing dilution at (a) $5 \%$, (b) $18 \%$, (c) $24 \%$ and (d) $34 \%$ respectively (yellow lines $=\mathrm{Fe}-\mathrm{Cu}$ boundary).
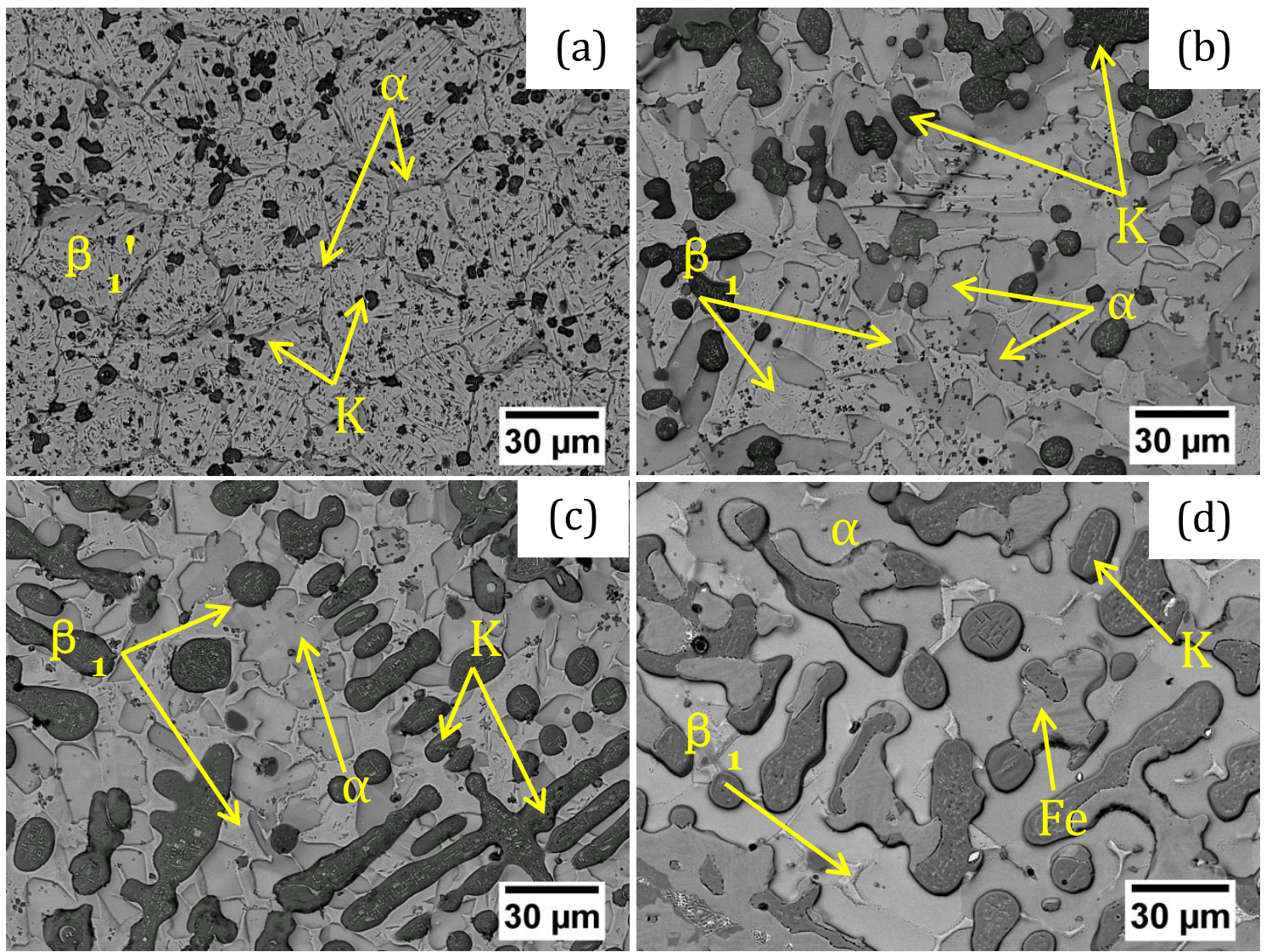

Figure 2: Plane viewed BSE images of PTA aluminium bronze coatings of increasing dilution at (a) $5 \%$, (b) $18 \%$, (c) $24 \%$ and (d) $34 \%$ respectively. Electro-polish was the final preparation for the coating surface observation. 



(c)

(d)

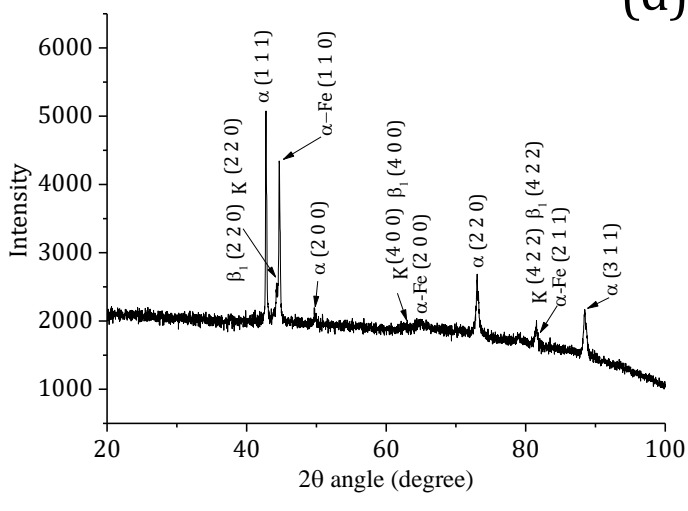

Figure 3: XRD patterns showing the effects of increasing dilution on the identified phases in the PTA aluminium bronze coating (a) $5 \%$, (b) $18 \%$, (c) $24 \%$ and (d) $34 \%$ dilution

The EDS analysis in Table 4 confirms that the two matrix phases are high in $\mathrm{Cu}$ and $\mathrm{Al}$. The two phases can be distinguished by the difference in $\mathrm{Al}$ of 2.6-6.1 wt.\% (4.9-10.4 in at.\%). The $\mathrm{Al}$ content affects the electrochemical potential of the phase leading to the observed difference in removal rate during electro-polishing as shown in Figure 2. For all coatings the areas removed by the electro-polishing were identified as the solid solution $\alpha$ phase. The unaffected areas of the matrix have a stoichiometric $\mathrm{Cu}: \mathrm{Al}$ ratio of approximately $3: 1$. In the 5\% dilution coating, XRD in conjunction with EDS analysis confirms the $\mathrm{Cu}_{3} \mathrm{Al}$ phase as $\beta_{1}{ }^{\prime}$ orthorhombic structure with the lattice parameters of $a=0.449 \mathrm{~nm}, b=0.519$ $\mathrm{nm}$ and $c=3.820 \mathrm{~nm}$, in agreement with previous TEM observation of water quenched $\mathrm{Cu}-11.7 \mathrm{Al}$ wt.\% alloy [15]. With increasing dilution, the unaffected areas were identified by XRD pattern in Figure $3 \mathrm{~b}-\mathrm{d}$ as the order $\beta_{1}$ phase consistent with the $\mathrm{D0}_{3}(\mathrm{Fm} \overline{3} \mathrm{~m})$ structure with the lattice parameter of $a=$ $0.582 \mathrm{~nm}$.

Based on the $\mathrm{Cu}-\mathrm{Al}$ phase diagram, when quenching from the $\beta$ state, The high temperature disordered $\beta$ phase first undergoes an ordering reaction into an ordered $\beta_{1}$ phase and then martensitic transformation into $\beta_{1}{ }^{\prime}[9,16]$. It indicates that the ordered $\beta_{1}$ phase is formed at higher temperature than the martensitic $\beta_{1}{ }^{\prime}$ phase. This can explain the change of $\mathrm{Cu}$-rich phase from martensitic $\beta_{1}$ phase (Figure $2 \mathrm{a}$ ) to the $\beta_{1}$ 
phase (Figure $2 \mathrm{~b}-\mathrm{d}$ ), as the $\beta_{1}{ }^{\prime}$ was observed in the dilution $5 \%$ by deposition current of $170 \mathrm{~A}$ which is the lowest current thus melting temperature. Further cooling at low temperature also resulted in the formation of fine intermetallic compounds as observed in Figure 2a.

Table 4: EDS analysis of the intermetallic and the constituent phases in the aluminium bronze coating (all in wt.\%)

\begin{tabular}{l|l|c|c|c|c}
\hline $\begin{array}{l}\text { Percentage } \\
\text { dilution }\end{array}$ & Phases & $\mathrm{Cu}$ & $\mathrm{Al}$ & $\mathrm{Fe}$ & Phases identified \\
\hline \multirow{3}{5}{$\%$} & Removed & 89.8 & 8.8 & 1.5 & $\alpha$ \\
\cline { 2 - 6 } & Unaffected & 86.8 & 11.4 & 1.7 & $\beta_{1}{ }^{{ }^{\prime}}$ \\
\cline { 2 - 6 } & Intermetallic & 19.3 & 13.9 & 66.7 & $\mathrm{~K}$ \\
\hline \multirow{3}{*}{$18 \%$} & Removed & 88.9 & 8.2 & 2.9 & $\alpha$ \\
\cline { 2 - 6 } & Unaffected & 86.4 & 11.5 & 2.1 & $\beta_{1}$ \\
\cline { 2 - 6 } & Intermetallic & 16.7 & 8.6 & 74.7 & $\mathrm{~K}$ \\
\hline \multirow{2}{*}{$24 \%$} & Removed & 88.5 & 8.1 & 3.3 & $\alpha$ \\
\cline { 2 - 6 } & Unaffected & 86.2 & 11.2 & 2.6 & $\beta_{1}$ \\
\cline { 2 - 6 } & Intermetallic & 14.5 & 3.1 & 82.4 & $\mathrm{~K}$ \\
\hline \multirow{3}{*}{$34 \%$} & Removed & 84.6 & 9.6 & 5.8 & $\alpha$ \\
\cline { 2 - 6 } & Unaffected & 80.0 & 15.7 & 4.3 & $\beta_{1}$ \\
\cline { 2 - 6 } & Intermetallic & 11.9 & 8.2 & 79.9 & $\mathrm{~K}$ \\
\cline { 2 - 6 } & Light grey area in Figure 2d & 12.3 & 6.6 & 81.2 & $\alpha-\mathrm{Fe}$ \\
\hline
\end{tabular}

We converted (greyscale) SEM-BSE images of the electro-polished condition of Figure 2a-d into binary images, which allowed the volume fractions of the constituent phases in the coating to be determined using image analysis. The results are presented in Table 5. With increasing dilution from $18 \%$ to $34 \%$, the volume fraction of the $\alpha$ phase in the coating increased significantly, while the volume of fraction of the $\beta_{1}$ decreased. This indicates that with increasing $\mathrm{Fe}$, the composition of the coating is shifted towards the solid solution region of the $\mathrm{Cu}-\mathrm{Al}$ phase diagram.

Table 5: The effects of substrate dilution on the volume fraction of the constituent phases in PTA aluminium bronze coating as determined by image analysis of the coating in electro-polished condition

\begin{tabular}{c|c|c|c|c|c}
\hline $\begin{array}{c}\text { Percentage } \\
\text { dilution \% }\end{array}$ & $\alpha$ phase & $\beta_{1}$ & $\beta_{1}{ }^{\prime}$ & $\mathrm{K}$ & $\alpha$-Fe \\
\hline 5 & 5.8 & - & 80.2 & 14.0 & - \\
\hline 18 & 29.5 & 51.3 & - & 19.2 & - \\
\hline 24 & 33.7 & 28.1 & - & 38.3 & - \\
\hline 34 & 48.9 & 2.2 & - & 25.4 & 23.4 \\
\hline
\end{tabular}

\subsection{Effects of dilution on the hardness of PTA aluminium bronze coating}

The effects of dilution on the hardness distribution of the coatings are shown in Figure 4. At the lowest dilution of $5 \%$ the hardness is the most uniform with mean hardness of $~ 500 \mathrm{HV}$. With increasing dilution, the hardness of the coating is less homogenous due to the coarse intermetallic. By imaging the indent maps in BSE electron mode, the hardness of the constituent phases in the coatings were obtained 
and the results are presented in Table 6. Due to the fine size of the $\mathrm{Fe}_{3} \mathrm{Al} \mathrm{K}$ and $\alpha$ phase in the 5\% dilution coating (Figure 2a), accurate measurements of these phases were not possible.

(a)

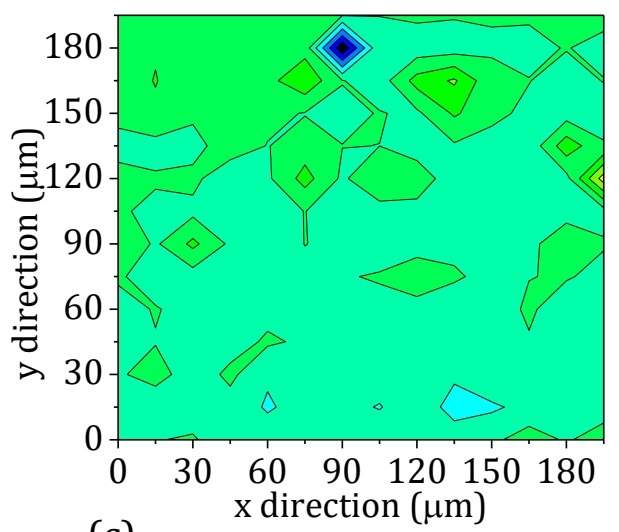

(c)

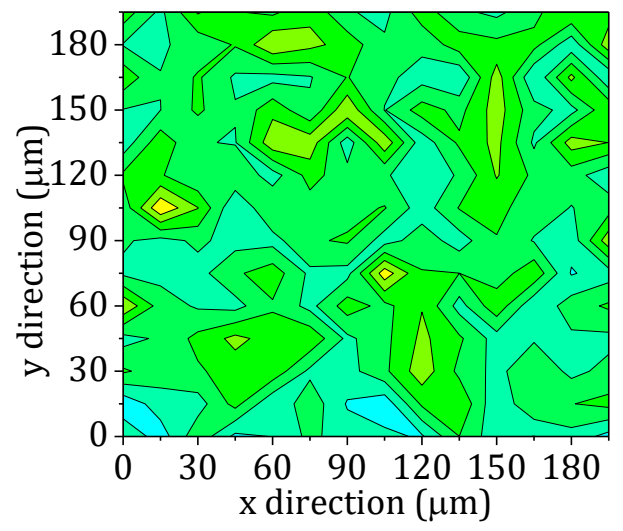

(b)

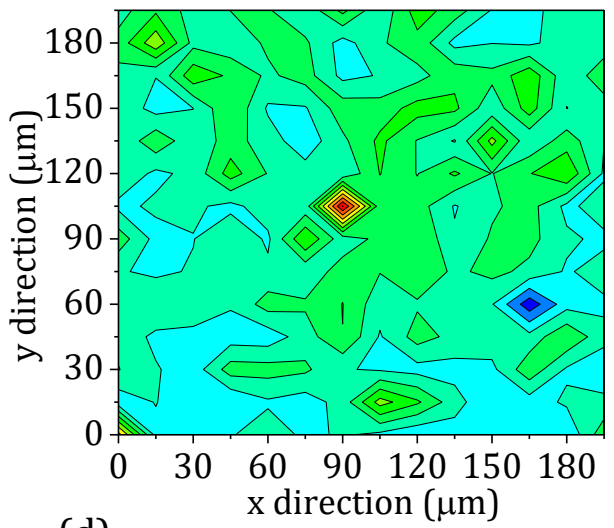

(d)

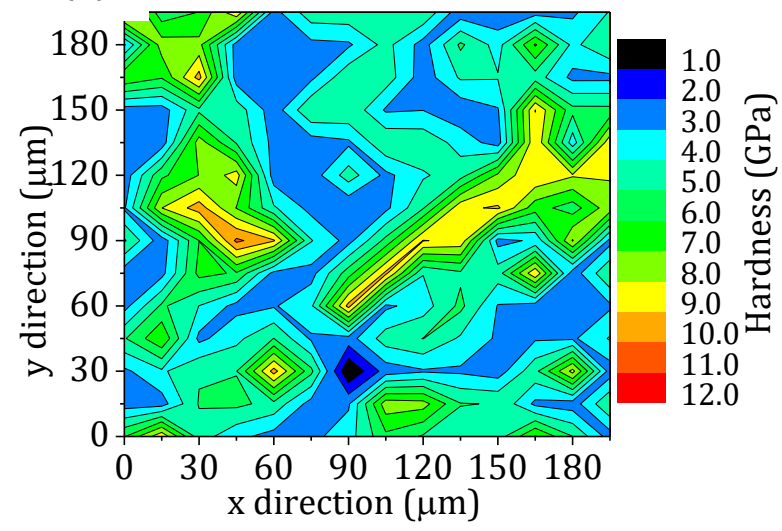

Figure 4: 2D plot of measured hardness from 196 indent points on the surface of PTA aluminium bronze coatings with (a) $5 \%$, (b) $18 \%$, (c) $24 \%$ and (d) $34 \%$ dilution

Table 6: The effects of dilution on the measured hardness (in HV) of the phases present in the PTA aluminium bronze coatings

\begin{tabular}{l|c|c|c|c}
\hline Percentage dilution & $5 \%$ & $18 \%$ & $24 \%$ & $34 \%$ \\
\hline$\alpha$ phase hardness & - & 357 & 367 & 265 \\
\hline$\beta_{1}$ phase hardness & - & 459 & 439 & - \\
\hline K phase hardness & - & 632 & 724 & 489 \\
\hline$\alpha$-Fe hardness & 499 & 479 & 571 & 826 \\
\hline $\begin{array}{l}\text { Mean hardness from 196 } \\
\text { indents }\end{array}$ & & & & 469 \\
\hline
\end{tabular}

\subsection{The effects of dilution on dry sliding friction and wear characteristics}

The changes in microstructure promoted by dilution have significant impacts on the dry sliding friction coefficient of the coatings as shown in Figure 5. For all coatings, the friction coefficient decreased with increasing load, this is the most apparent for the coating with highest dilution as shown in Figure 5d. 
An initial spike in friction coefficient was also observed, this apparent in coatings with 5\%, 18\% and 24\% dilution as shown Figure 5 a-c. This initial rise in friction coefficient has also been observed in reference [17] and can be attributed to the build-up of film or debris at the contact region. The build-up of film is evident as an increase in oxygen in the worn surface as shown in by EDS results in Figure 6. Up to $24 \%$ dilution, the worn surfaces were less oxidised and a significant increase in oxidation was observed at $34 \%$ dilution. This increase in oxidation is evident as a compacted layer (appearing dark) in Figure 6e confirmed as rich in Fe and $\mathrm{O}$ by EDS analysis. The formation of Fe-oxide tribofilm layer was due to the strong cohesion between the Fe-rich coating and the bearing steel and high friction coefficient in the $34 \%$ dilution coating.

(a)

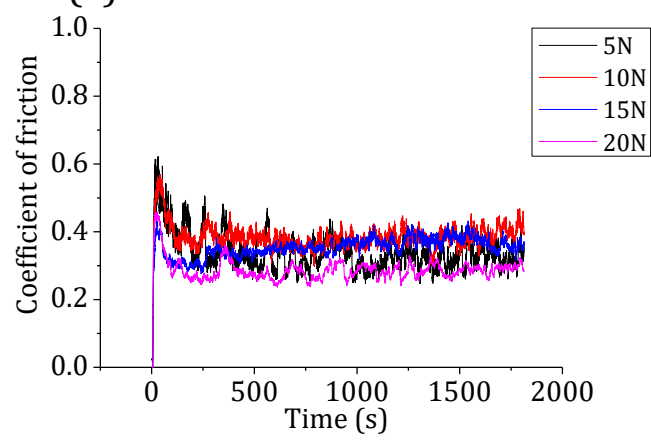

(c)

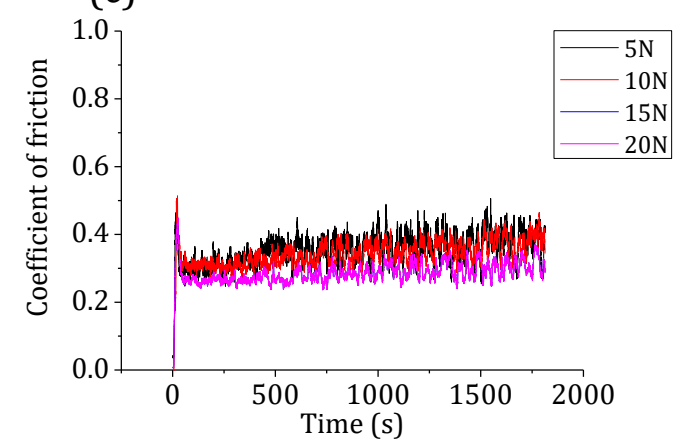

(b)

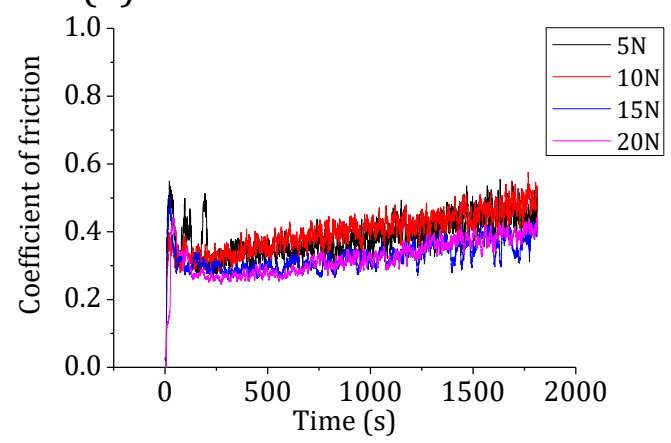

(d)

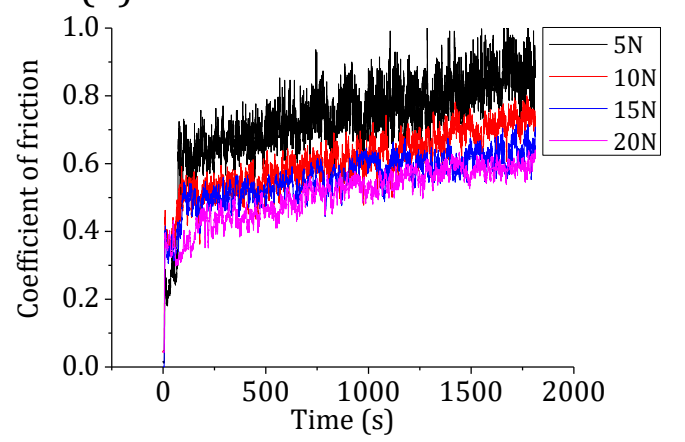

Figure 5: Measured coefficient of friction during dry reciprocating sliding between AISI52100 and the PTA aluminium bronze coatings (a) $5 \%$, (b) $18 \%$, (c) $24 \%$ and (d) $34 \%$ 
(a)

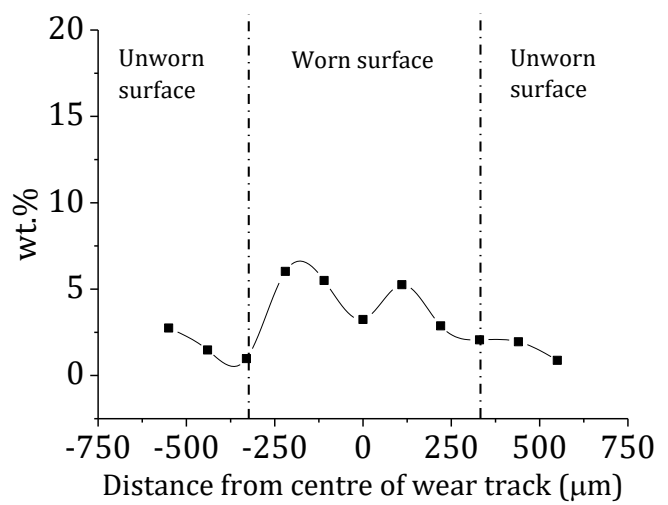

(c)

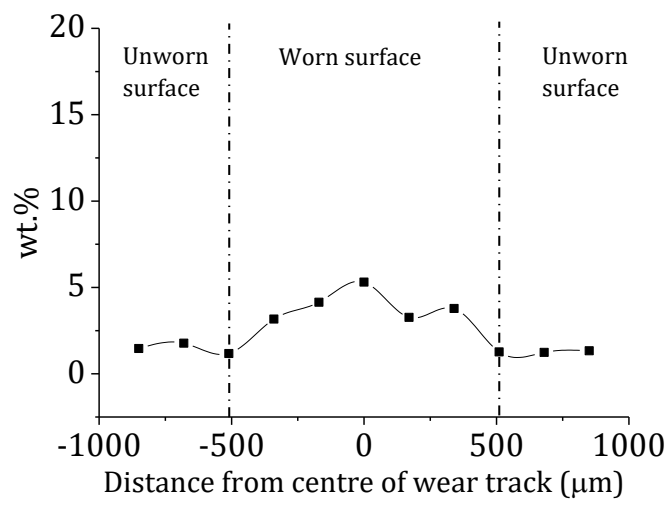

(b)

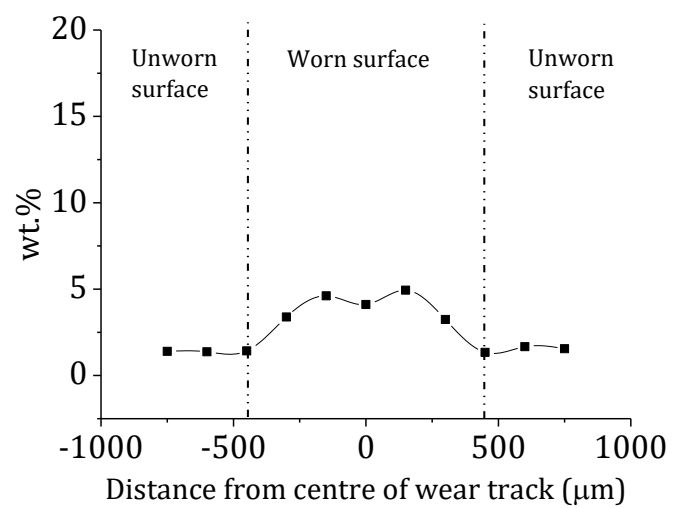

(d)

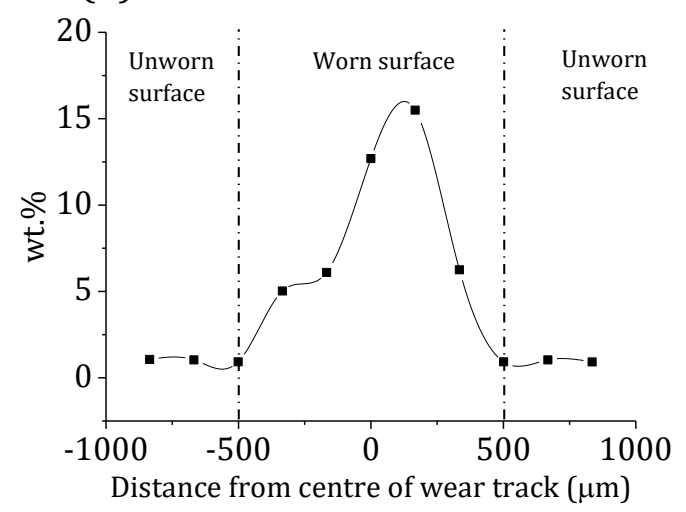

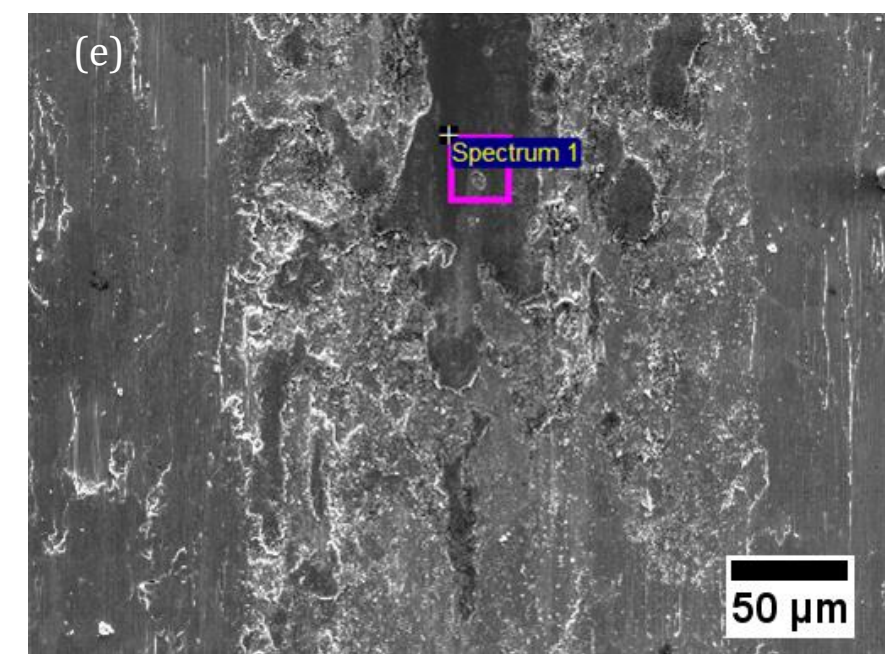

EDS analysis of the compacted mechanically mixed layer on 34\% dilution coating (all in wt.\%)

\begin{tabular}{|l|l|l|l|l|l|}
\hline $\mathrm{Fe}$ & $\mathrm{Cu}$ & $\mathrm{Al}$ & 0 & $\mathrm{Cr}$ & $\mathrm{Si}$ \\
\hline 58.6 & 7.0 & 1.8 & 31.4 & 1.0 & 0.3 \\
\hline
\end{tabular}

Figure 6: EDS analysis showing the change in O concentration across the wear track of the PTA aluminium bronze coatings with (a) $5 \%$, (b) $18 \%$, (c) $24 \%$ and (d) $34 \%$ dilution. (e) lists the tribofilm compositions from the worn surface of the $34 \%$ dilution coating.

The microstructure promoted by dilution changes the wear mechanism of the coatings as shown by the low magnification SE images of the wear scars in Figure 7. At 5\% dilution (Figure 7a), abrasive wear 
dominates. With increasing dilution, the dominant wear mechanism changes from abrasive to adhesive wear as evident by the large wear debris shown in Figure $7 \mathrm{~b}$ and $7 \mathrm{c}$. The $34 \%$ dilution coating shows a complex wear track consisting of some polished patches which were confirmed as Fe-O oxidation films, which were similar to the observation in the Ni-MoS 2 coatings [18].

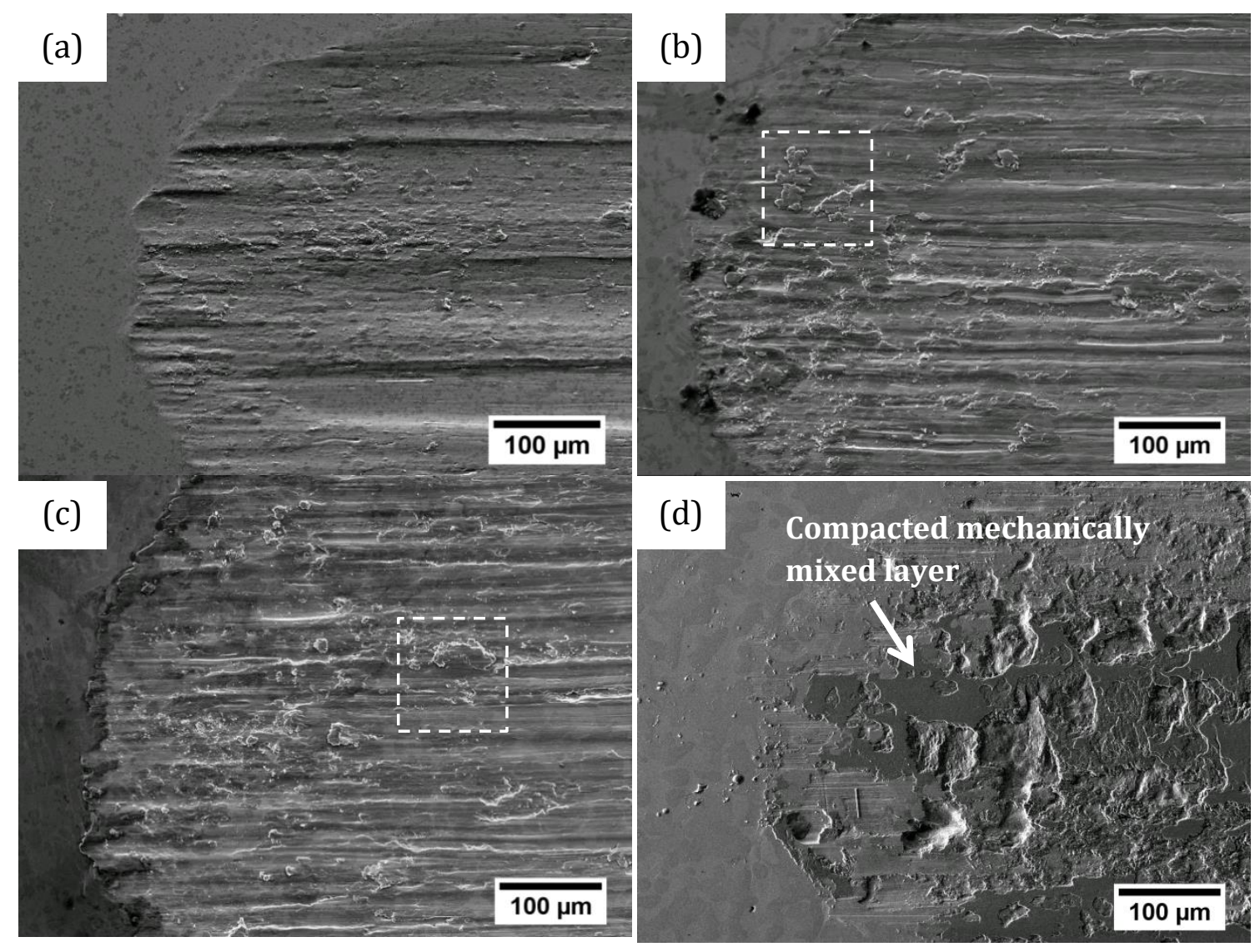

Figure 7: Secondary electron images of the worn PTA aluminium bronzes coating worn against AISI 52100 tested at $5 \mathrm{~N}$ (box highlights wear debris) (a) 5\%, (b) 18\%, (c) $24 \%$ and (d) $34 \%$ dilution

Detailed observations of the worn surface of the $18 \%, 24 \%$ and $34 \%$ dilution coatings reveal the presence of surface cracks (an example of 18\% shown in Figure 8). However, these cracks were not observed in the $5 \%$ dilution coating, which has a martensitic $\beta_{1}^{\prime}$ phase matrix. In previous studies on wear of aluminium bronze alloys $[19,20]$, subsurface cracks were observed underneath the worn surface. To investigate whether subsurface cracks are also present in the PTA aluminium bronze coating, selected worn surfaces of the 5\% (martensitic matrix) and 24\% (solid solution matrix) were sectioned using FIB and observed using ion imaging as shown in Figure 9a and 9b respectively.

In the $5 \%$ coating with $\beta_{1}{ }^{\prime}$ martensitic matrix, the microstructure underneath the worn surface is characterised by a layer of fine grains nanometre in size as shown in Figure 9a. Dynamic recrystallization (DRX) induced during dry sliding wear test is thought to be the mechanism responsible for generation of the nanometre sized grain. The presence of DRX in $\mathrm{Cu}$ alloys was first reported in 
[21] and confirmed by TEM during sliding wear of $\mathrm{Cu}$ pins against steel [22]. Beneath the fine grain layer, the microstructure of the martensite appears to be un-affected and the morphology of the K phase appears to retain the same morphology as in the un-deformed alloy (Figure 2a). A possible reason for the limited deformation of the martensite could be due to the energy dissipation among the interfaces within the martensite plates and matrix [17]. No subsurface cracks were observed.

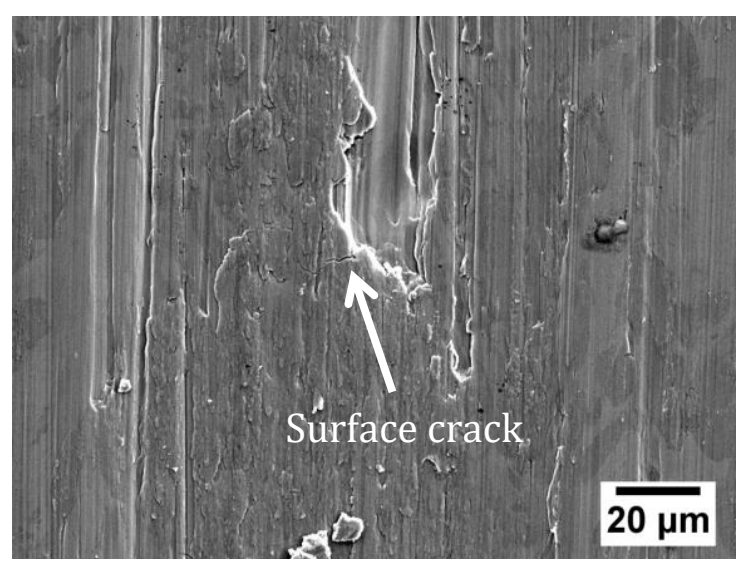

Figure 8: SE image showing surface cracks on the surface of $18 \%$ dilution coating
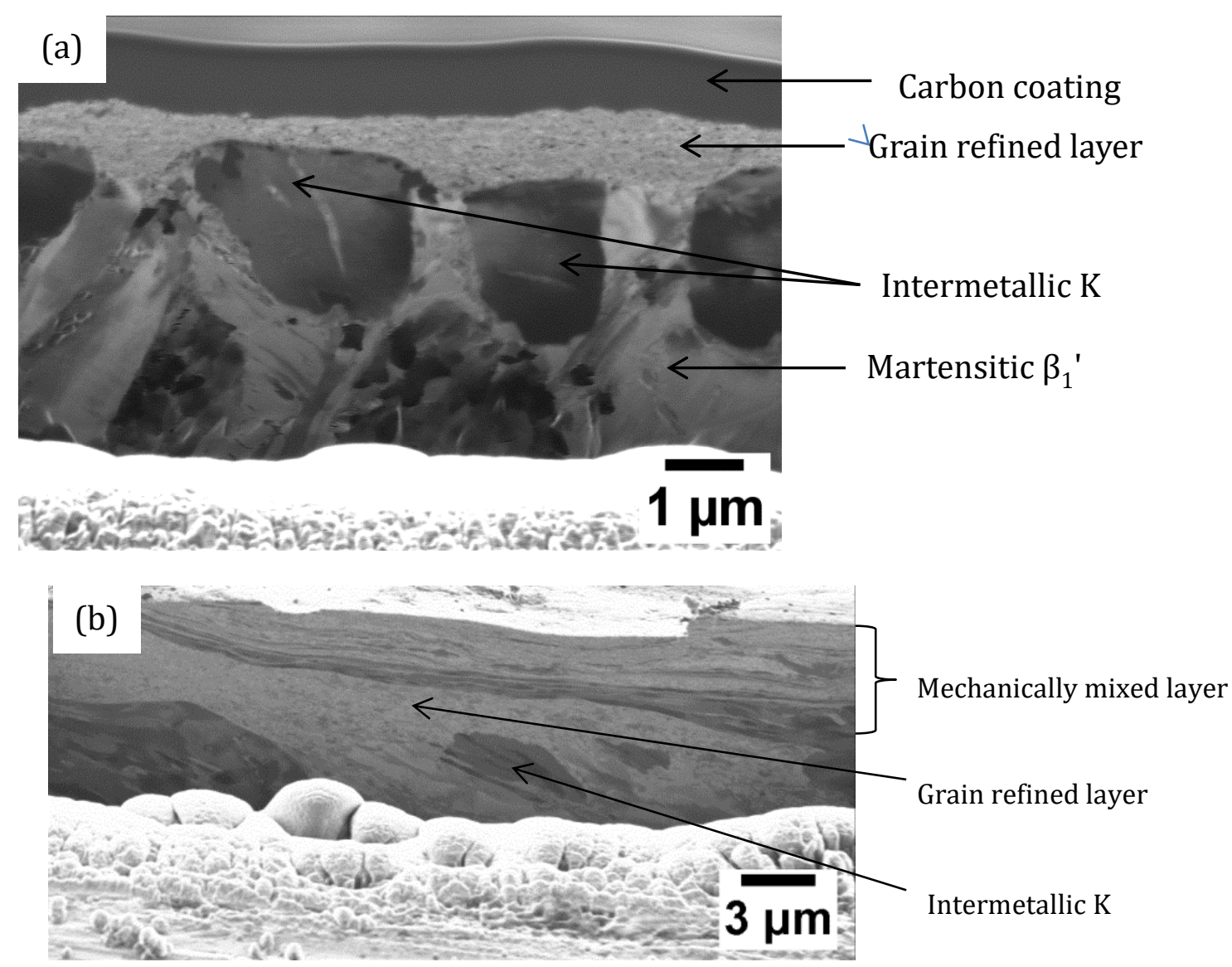

Figure 9: FIB cross section of the worn surface on (a) 5\% and (b) 24\% dilution PTA aluminium bronze coatings against AISI 52100 by $5 \mathrm{~N}$ load. 
The subsurface microstructure of the 24\% dilution coating is shown in Figure 9b. Two distinct regions can be identified. Underneath the worn surface is a mechanically mixed layer, which is a mixture of the substrate and the oxide layers (see oxygen profile in Figure 6c) that have been sheared and worked back on to the surface during sliding. Beneath the mechanically mixed layer is a grain refined layer of nanometre in size. In the fine grain layer, significant plastic flow was also observed. This is evident by the elongation of the intermetallic $\mathrm{K}$ phase. The observed microstructure is similar to that reported in [23], however unlike previous observations, no subsurface cracks were observed.

In the 5\% dilution coating with a martensitic matrix, no cracks or slip lines were observed. However, surface cracks were observed in the $18 \%, 24 \%$ and $34 \%$ dilution coatings, which were related to the slip of $\alpha$ phase matrix against the non-deformed intermetallics. Figure 10 is high magnification BSE images showing a representative microstructure at the boundary between worn and unworn surface of the $24 \%$ dilution coating. Surface cracks and slip lines, which terminate at the intermetallic phase, were observed. The presence of slip can be explained by the crystal structure of the matrix phase. X-ray diffraction and EDS results confirmed that the solid solution $\alpha$ phase is the dominant phase in these coatings. The inverse pole figure in Figure 10 show strong texture on the $\{111\}$ plane in the $\mathrm{z}$ direction, which is the dominate slip plane for the $\alpha$ phase matrix that has a face central cubic crystal structure. Upon loading in the $\mathrm{z}$ direction, the materials will begin to slip along the preferential slip plane similar to the sliding of a deck of card resulting in the observed slip lines such as those shown. Termination of slip lines at the intermetallic phase indicates pile-up of dislocation at the harder intermetallic phase. This results in the formation of the observed surface cracks such as those shown in Figure 8. This leads to delamination of materials in the form of thin sheet as shown in Figure 11a. The shape of debris in Figure $11 \mathrm{~b}$ suggest they were predominantly formed by delamination rather than any other wear mechanism. 




Figure 10: BEI image showing pile up of slip lines at intermetallic phase resulting in cracks on surface of $24 \%$ dilution coating

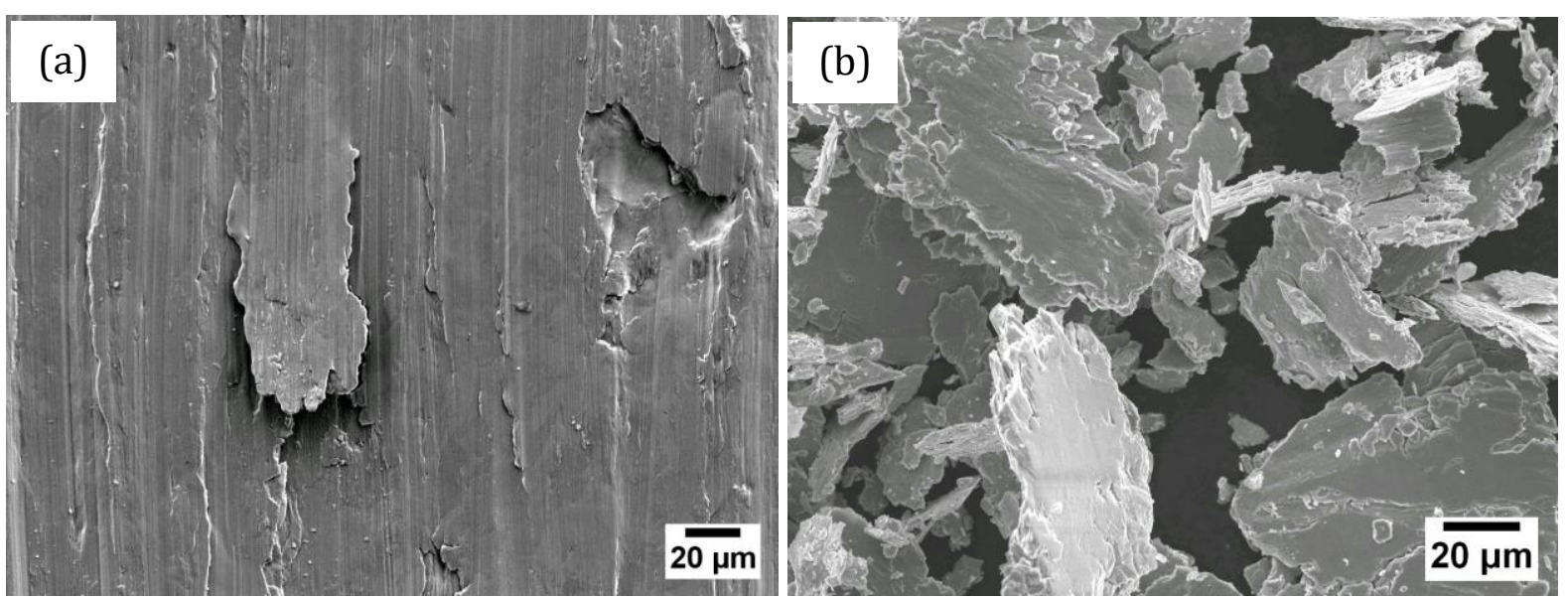

Figure 11: SE image of the $24 \%$ dilution coating showing (a) peeling off surface, (b) wear debris 
Consequently, the 5\% dilution coating has the lowest specific wear rate as shown in shown in Figure 12. The increase in dilution above $5 \%$ to $18 \%$ leads to an increase in specific wear rate. The $24 \%$ dilution coating exhibits the highest wear rate despite having the highest hardness as shown in Table 5. At 34\% dilution the specific wear rate decreased. This is not expected. The apparent reduction in wear rate is due to the formation of the compacted mechanical polished layer (shown in Figure 7d) from the worn debris. This layer will stick in the worn track and thus reduce the mass loss and the specific wear rate.

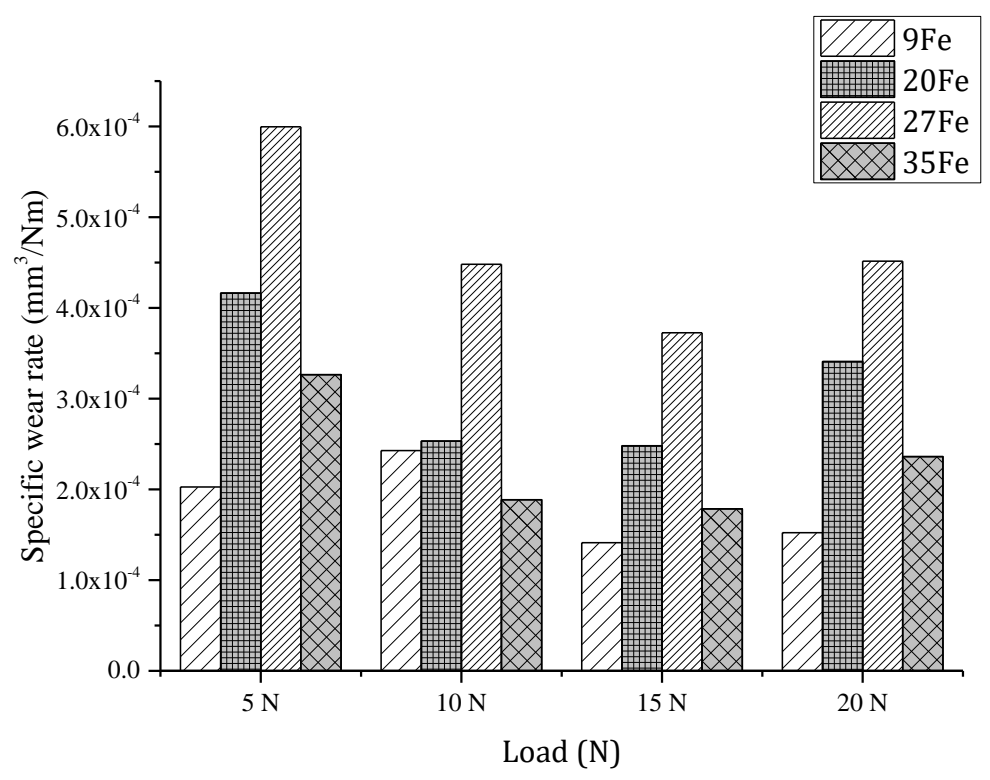

Figure 12: The effects of PTA induced Fe increase on the specific wear rate of the coating worn against AISI52100 bearing steel

\section{Conclusion}

PTA induced dilution leads to significant changes to the microstructure of $\mathrm{Cu}-\mathrm{Al}-\mathrm{Fe}$ aluminium bronze coating. At low dilution of $5 \%$, corresponding to $\mathrm{Fe}<10 \mathrm{wt} . \%$, the resulting coating has a martensitic $\beta_{1}^{\prime}$ microstructure with submicron size intermetallic $\mathrm{K}$ phase. With increasing in dilution resulting in an increase in Fe of more than $10 \mathrm{wt} . \%$ in the coating, the resulting coating has a $\alpha+\beta_{1}$ microstructure with intermetallic $\mathrm{K}$ phase of several microns in size. The wear behaviour of the coating is controlled by failure of the matrix phase. The coating with a martensitic $\beta_{1}{ }^{\prime}$ phase and submicron size intermetallic $\mathrm{K}$ phase has the lowest specific wear rate. Coatings with $\alpha+\beta_{1}$ matrix phase and large intermetallic K phase have high wear rate. Pile-up of dislocation at the intermetallic phase leads to formation of voids and surface cracks. Coalescence of surface cracks subsequently leads to the delamination of the coating, 
resulting in high wear rate. With the increase of Fe content for the dilution of $34 \%$, the wear rate is reducing due to the formation of the compacted debris film.

\section{Acknowledgements}

The authors acknowledge financial support by the Royal Society International Exchanges Scheme (IE151191) and the EPSRC Global Challenge Research Fund.

\section{References}

[1] ASTM G40-13 Terminology relating to wear and erosion, in ASTM Annual Book of Standards Vol .03.02, West Conshohocken PA, 2013.

[2] N. Bay, A. Azushima, P. Groche, I. Ishibashi, M. Merklein, M. Morishita, T. Nakamura, S. Schmid, M. Yoshida, Environmentally benign tribo-systems for metal forming, CIRP Ann. - Manuf. Technol. 59 (2010) 760-780. https://doi.org/10.1016/j.cirp.2010.05.007.

[3] K.G. Budinski, S.T. Budinski, Interpretation of galling tests, Wear. 332-333 (2015) 1185-1192. https://doi.org/10.1016/j.wear.2015.01.022.

[4] W.S. Li, Z.P. Wang, Y. Lu, Y.H. Jin, L.H. Yuan, F. Wang, Mechanical and tribological properties of a novel aluminum bronze material for drawing dies, Wear. 261 (2006)155-163. https://doi.org/10.1016/j.wear.2005.09.032.

[5] V. Balasubramanian, A.K. Lakshminarayanan, R. Varahamoorthy, S. Babu, Application of response surface methodolody to prediction of dilution in plasma transferred arc hardfacing of stainless steel on carbon steel, J. Iron Steel Res. Int. 16 (2009) 44-53. https://doi.org/10.1016/S1006-706X(09)60009-1.

[6] F. Fernandes, T. Polcar, A. Loureiro, A. Cavaleiro, Effect of the substrate dilution on the room and high temperature tribological behaviour of Ni-based coatings deposited by PTA on grey cast iron, Surf. Coatings Technol. 281 (2015) 11-19. https://doi.org/10.1016/j.surfcoat.2015.09.034.

[7] L.J. da Silva, A.S.C. M.D'Oliveira, NiCrSiBC coatings: Effect of dilution on microstructure and high temperature tribological behavior, Wear. 350-351 (2016) 130-140. https://doi.org/10.1016/j.wear.2016.01.015.

[8] M.S. Sawant, N.K. Jain, Investigations on wear characteristics of Stellite coating by micro-plasma transferred arc powder deposition process, Wear. 378-379 (2017) 155164. https://doi.org/10.1016/j.wear.2017.02.041.

[9] H. Kwarciak, J. Bojarski, Z. Morawiec, Phase transformation in martensite of Cu12.4\% Al, J. Mater. Sci. 21 (1986) 788-792. https://doi.org/10.1007/BF01117355.

[10] A.T. Adorno, M.R. Guerreiro, A. V. Benedetti, Isothermal aging kinetics in the Cu-19 at.\%Al alloy, J. Alloys Compd., 150-157 (315) 2001. https://doi.org/10.1016/S09258388(00)01268-8. 
[11] W.S. Li, Z.P. Wang, L.H. Yuan, Preparation, mechanical properties and wear behaviors of novel aluminum bronze for dies, Trans. Nonferrous Met. Soc. China, 16 (2005) 607-612. https://doi.org/10.1016/S1003-6326(06)60107-6.

[12] P.J. Macken, The Aluminium Bronzes. Copper Development Association, 1966.

[13] A.K. Lakshminarayanan, V. Balasubramanian, R. Varahamoorthy, S. Babu, Predicting the dilution of plasma transferred arc hardfacing of stellite on carbon steel using response surface methodology, Met. Mater. Int., 14 (2008) 779-789. https://doi.org/10.3365/met.mat.2008.12.779.

[14] F. Fernandes, B. Lopes, A. Cavaleiro, A. Ramalho, A. Loureiro, Effect of arc current on microstructure and wear characteristics of a Ni-based coating deposited by PTA on gray cast iron, Surf. Coatings Technol., 205 (2011) 4094-4106. https://doi.org/10.1016/j.surfcoat.2011.03.008.

[15] K. Zenji, N. Setsuo, Electron microscope study of the crystal structure of the martensite in a copper-aluminium alloy, Jpn. J. Appl. Phys., 2 (1963) 478-486.

[16] N. Nakanishi, The Crystal Structure of B' Martensite in Cu-Al Binary Alloys, Trans. JIM, 2 (1960) 79-86.

[17] P.J. Blau, Effect of heat treatment and electron beam surface melting on the friction and wear behavior of a Cu-12wt.\% Al Alloy, Wear, 94 (1984) 1-12. https://doi.org/10.1016/0043-1648(84)90163-7.

[18] Y. He, S.C. Wang, F.C. Walsh, Y.L. Chiu, P.A.S. Reed, Self-lubricating Ni-P-MoS2 composite coatings, Surf. Coatings Technol., 307 (2016) 926-934. https://doi.org/10.1016/j.surfcoat.2016.09.078.

[19] Z. Shi, Y. Sun, A. Bloyce, T. Bell, Unlubricated rolling-sliding wear mechanisms of complex aluminium bronze aganist steel, Wear, 193 (1996) 235-241. https://doi.org/10.1016/0043-1648(95)06773-6.

[20] J.J. Pamies-Teixeira, N. Saka, N.P. Suh, Wear of copper-based solid solutions, Wear, 44 (1977) 65-75. https://doi.org/10.1016/0043-1648(77)90085-0.

[21] R.C. Bill, D. Wisander, Recrystallization as a controlling process in the wear of some F.C.C. metals, Wear, 41 (1977) 351-363. https://doi.org/10.1016/00431648(77)90013-8.

[22] J. Dautzenberg, The role of dynamic recrystallization in dry sliding wear, Wear, 60 (1980) 401-411. https://doi.org/10.1016/0043-1648(80)90238-0.

[23] X. Chen, Z. Han, K. Lu, Wear mechanism transition dominated by subsurface recrystallization structure in $\mathrm{Cu}-\mathrm{Al}$ alloys, Wear, 320 (2015) 41-50.

https://doi.org/10.1016/j.wear.2014.08.010. 